\title{
Positive correlation of airway resistance and serum asymmetric dimethylarginine level in COPD patients with systemic markers of low-grade inflammation
}

\author{
This article was published in the following Dove Press journal: \\ International Journal of COPD \\ 14 March 2017 \\ Number of times this article has been viewed
}

\author{
Gabor Tajti ${ }^{1,2}$ \\ Rudolf Gesztelyi ${ }^{3}$ \\ Krisztian Pak ${ }^{3}$ \\ Csaba Papp ${ }^{1}$ \\ Sandor Keki ${ }^{4}$ \\ Magdolna Emma Szilasi \\ Angela Mikaczo ${ }^{2}$ \\ Andrea Fodor ${ }^{2}$ \\ Maria Szilasi \\ Judit Zsuga' \\ 'Department of Health Systems \\ Management and Quality Management \\ for Health Care, Faculty of Public \\ Health, ${ }^{2}$ Department of Pulmonology, \\ Faculty of Medicine, ${ }^{3}$ Department of \\ Pharmacology and Pharmacotherapy, \\ Faculty of Medicine, ${ }^{4}$ Department \\ of Applied Chemistry, Faculty of \\ Science and Technology, University of \\ Debrecen, Debrecen, Hungary
}

\begin{abstract}
The major feature of COPD is a progressive airflow limitation caused by chronic airway inflammation and consequent airway remodeling. Modified arginase and nitric oxide synthase (NOS) pathways are presumed to contribute to the inflammation and fibrosis. Asymmetric dimethylarginine (ADMA) may shunt L-arginine from the NOS pathway to the arginase one by uncoupling and competitive inhibition of NOS and by enhancing arginase activity. To attest the interplay of these pathways, the relationship between ADMA and airflow limitation, described by airway resistance $\left(\mathrm{R}_{\mathrm{aw}}\right)$, was investigated in a cohort of COPD patients. Every COPD patient willing to give consent to participate $(n=74)$ was included. Case history, laboratory parameters, serum arginine and ADMA, pulmonary function (whole-body plethysmography), and disease-specific quality of life (St George's Respiratory Questionnaire) were determined. Multiple linear regression was used to identify independent determinants of $\mathrm{R}_{\mathrm{aw}}$. The final multiple model was stratified based on symptom control. The $\log \mathrm{R}_{\mathrm{aw}}$ showed significant positive correlation with log ADMA in the whole sample (Pearson's correlation coefficient: 0.25 , $P=0.03)$. This association remained significant after adjusting for confounders in the whole data set $(\beta$ : 0.42 ; confidence interval [CI]: $0.06,0.77 ; P=0.022)$ and in the worse-controlled stratum ( $\beta$ : 0.84 ; CI: $0.25,1.43 ; P=0.007)$. Percent predicted value of forced expiratory flow between $25 \%$ and $75 \%$ of forced vital capacity showed that significant negative, elevated C-reactive protein exhibited significant positive relationship with $\mathrm{R}_{\mathrm{aw}}$ in the final model. Positive correlation of $\mathrm{R}_{\mathrm{aw}}$ with ADMA in COPD patients showing evidence of a systemic low-grade inflammation implies that ADMA contributes to the progression of COPD, probably by shunting L-arginine from the NOS pathway to the arginase one.
\end{abstract}

Keywords: ADMA, airway resistance, nitric oxide, SGRQ, whole-body plethysmography

\section{Introduction}

COPD is projected to become the third most common cause of death and the seventh leading cause of disability-adjusted life years by $2030 .{ }^{1}$ Furthermore, COPD poses great direct economic burden, as $3.36 \%$ of total health care budget is estimated to be allocated for covering the direct costs of COPD management. ${ }^{2}$ Despite immense efforts, the complex pathological mechanisms underlying COPD are incompletely understood yet.

The key symptom of COPD is a persistent airflow limitation that progresses over time paralleled by prolonged and abortive inflammatory response in the airways given inhaled irritant particles (eg, smoke) ${ }^{3}$ and low-grade systemic inflammation. ${ }^{4} \mathrm{Chronic}$
Department of Health System Management and Quality Management for Health Care, Faculty of Public Health, University of Debrecen, Nagyerdei körút 98, 4032 Debrecen, Hungary

Tel +36306250144

Fax +36 $5241 \quad 1717$ (ext 55।87)

Email zsuga.judit@med.unideb.hu 


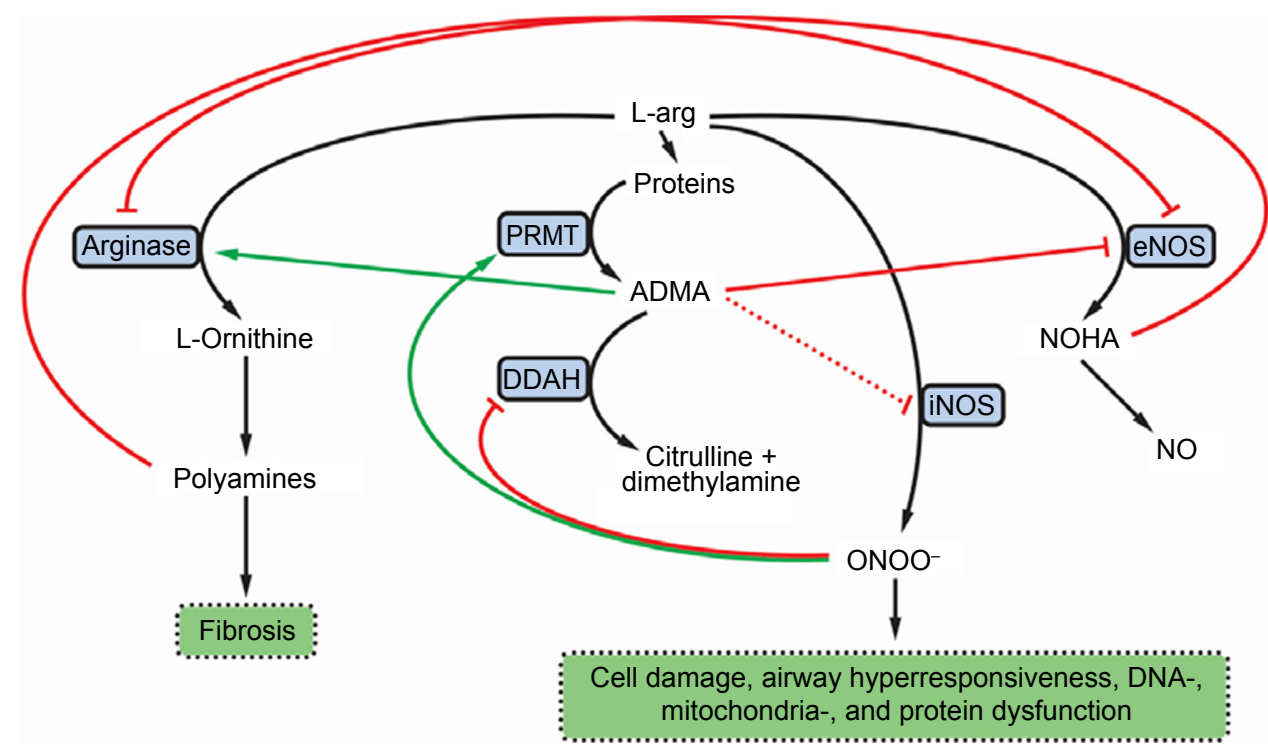

Figure I The influence of ADMA on the NOS and arginase pathways in COPD.

Notes: Green arrows denote activation and enhancement. Red lines denote inhibition. Black arrows denote transformation or metabolic connection.

Abbreviations: ADMA, asymmetric dimethylarginine; NOS, nitric oxide synthase; L-arg, L-arginine; NOHA, N-hydroxy-L-arginine; NO, nitric oxide; ONOO-', peroxynitrite anion; PRMT, protein methyltransferase; DDAH, dimethylarginine dimethylaminohydrolase (or dimethylargininase); eNOS, endothelial NOS; iNOS, inducible NOS.

inflammation causes oxidative stress and mostly irreversible structural changes manifested in emphysema and small airway fibrosis, ${ }^{5}$ both of which lead to persistent and progressive lower airway obstruction, the cause of airflow limitation (and consequent hypoxia). ${ }^{6}$ This altered tissue microenvironment enhances the metabolism of extracellular matrix components such as collagen. Given its high turnover, even small changes in collagen production may cause significant collagen accumulation. ${ }^{3}$

Modified arginase and nitric oxide synthase (NOS) pathways may contribute to the increased collagen formation and fibrosis in COPD (Figure 1). Expression of both arginase and inducible NOS (iNOS) was shown to be increased in COPD. Arginase inhibition was reported to prevent airway inflammation and remodeling in animal models of COPD. ${ }^{7}$ Accordingly, arginase activity exhibited significant negative correlation with spirometry parameters descriptive of airway flow (pre- and post-bronchodilator forced expiratory volume in $1 \mathrm{~s}$ as a percent of predicted value $\left[\mathrm{FEV}_{1} \%\right.$ pred] $){ }^{8}$

Asymmetric dimethylarginine (ADMA), an end product of degradation of methylated nuclear proteins, has diverse effects influential of the arginase and NOS pathways. ADMA has been shown to shunt L-arginine away from the NOS pathway toward the arginase path. In addition, ADMA induces uncoupling of NOS. The uncoupled NOS transfers electrons to ferrous-dioxygen, which eventually results in the formation of reactive oxygen and nitrogen species..$^{9,10}$ Previously, increased production of these reactive agents in response to ADMA was demonstrated in airway epithelium. ${ }^{11}$ ADMA, administered in vitro, was reported to increase oxidative stress and induce apoptosis. ${ }^{12}$ In addition, ADMA competitively inhibits NOS, thus limiting nitric oxide (NO) liberation. This latter effect is more pronounced for the constitutive isoforms, the endothelial and neuronal NOSs (eNOS and nNOS, respectively), than for iNOS, an effect reflected by a weak iNOS inhibition in cytokine-stimulated lung epithelial cells. ${ }^{13}$ Furthermore, ADMA was reported to enhance arginase activity and consequent collagen formation in lung fibroblasts. Moreover, ADMA infusion significantly increased airway resistance $\left(\mathrm{R}_{\mathrm{aw}}\right)$ and diminished dynamic compliance in response to methacholine in a murine model. ${ }^{14}$ The reciprocal regulation of arginase and $\mathrm{NOS}^{12}$ is further augmented by the interplay of intermediary products of these pathways: spermine, a byproduct of the arginase path, inhibits NOS, ${ }^{8}$ and N-hydroxy-L-arginine, a metabolite in the NOS pathway, blunts the arginase enzyme (Figure 1). ${ }^{15}$

Starting from the above-mentioned complex interactions among pathways, we set out to investigate the relationship between ADMA and airflow limitation described by $\mathrm{R}_{\mathrm{aw}}$ in a cohort of COPD patients.

\section{Methods}

\section{Study design and protocol}

The present study was planned in line with the STROBE statement for cross-sectional studies ${ }^{16}$ and was approved by the Ethical Committee of the University of Debrecen 
(DEOEC RKEB/IKEB 3632-2012). Informed consent was obtained from each participant. The investigation conforms to the principles outlined in the Declaration of Helsinki.

The current study is based on an investigation of patients who attended the outpatient unit of the Department of Pulmonology (University of Debrecen) between September 1, 2012 and October 15, 2013 for the management of any of the following chronic inflammatory airway diseases: bronchial asthma (BA), COPD, asthma-COPD overlap syndrome (ACOS), and allergic rhinitis (AR). All patients who did not have any acute inflammatory disease over the preceding 1 month and either benign or malignant tumors in the history were invited to participate in the study. Overall, 319 patients were recruited (BA: $n=167$, COPD: n=74, ACOS: $n=21$, and AR: $n=56$ ).

For the present study, data of patients who were treated for COPD $(n=74)$ were analyzed. At the time of recruitment, patients were already diagnosed with COPD and were managed according to the relevant Hungarian practice guideline ${ }^{17}$ and the Global initiative for chronic Obstructive Lung Disease (GOLD). ${ }^{18}$ Airway limitation was defined using the lower limit of normal. ${ }^{19-21}$ Patients received therapy at the time of inclusion as clinically warranted. Wholebody plethysmography was performed for every patient to determine lung function parameters including $\mathrm{R}_{\mathrm{aw}}$, which was selected as the main outcome measure. $\mathrm{R}_{\mathrm{aw}}$ is reflective of alterations in alveolar pressure over changes in flow and is highly dependent on state of airways, and thus, it is an optimal parameter for the quantification of airflow limitation. ${ }^{22}$ Demographic, anthropometric, anamnestic, laboratory, and quality-of-life data were also acquired. Cumulative measure of smoking exposure was described by pack-years (accounted for both past and current smoking exposure). To assess disease-specific quality of life, the official Hungarian version of St George's Respiratory Questionnaire (SGRQ) ${ }^{23}$ was used with the permission of the proprietor (Paul Jones, University of London, London, UK).

\section{Pulmonary function testing}

Whole-body plethysmography was performed according to the American Thoracic Society/European Respiratory Society criteria ${ }^{24,25}$ with Piston whole-body plethysmograph (PDT-111/p; Piston Medical, Budapest, Hungary) equipped with automatic body temperature- and pressure-saturated correction for cabin temperature, humidity, and pressure and with full automatic calibration and leakage test. Patients were directed to take their usual medication on the morning of their examination, so plethysmography was performed while patients were receiving long-term therapy for COPD. The best of three technically sound maneuvers was selected for each participant. Regarding resistance curves, at least two separate and technically appropriate measurements were performed (each measurement consisted of recordings of at least five resistance loops), and results were accepted only if these were the same for both measurements. Lung function data and, if algorithms of the manufacturer were available, percent predicted of normal reference values were obtained: $\mathrm{R}_{\mathrm{aw}}$, airway conductance $\left(\mathrm{G}_{\mathrm{aw}}=1 / \mathrm{R}_{\mathrm{aw}}\right), \mathrm{FEV}_{1} \%$ pred, forced vital capacity as a percent of predicted value ( $\mathrm{FVC} \%$ pred), ratio of $\mathrm{FEV}_{1}$ to $\mathrm{FVC}\left(\mathrm{FEV}_{1} / \mathrm{FVC}=\mathrm{FEV}_{1} \%=\right.$ Tiffeneau index), forced expiratory flow between $25 \%$ and $75 \%$ of FVC as a percent of predicted value $\left(\mathrm{FEF}_{25-75 \%} \%\right.$ pred), residual volume as a percent of predicted value (RV\% pred), total lung capacity as a percent of predicted value (TLC\% pred), ratio of $R V$ to TLC as a percent of predicted value (RV/ TLC $\%$ pred), ratio of inspiratory capacity to TLC (IC/TLC), inspiratory vital capacity as a percent of predicted value (IVC $\%$ pred), ratio of $\mathrm{FEV}_{1}$ to IVC as a percent of predicted value $\left(\mathrm{FEV}_{1} / \mathrm{IVC} \%\right.$ pred $)$, thoracic gas volume as a percent of predicted value ( $\mathrm{TGV} \%$ pred), peak expiratory flow as a percent of predicted value ( $\mathrm{PEF} \%$ pred), maximal expiratory flow at $50 \%$ of $\mathrm{FVC}$ as a percent of predicted value $\left(\mathrm{MEF}_{50 \%} \%\right.$ pred). Parameters showing Gaussian distribution were used in their raw forms, whereas those not normally distributed were appropriately transformed to obtain normal distribution.

\section{Blood samples}

After an overnight fast, blood samples were drawn on the morning of the examination. Routine laboratory investigations were done according to the standard clinical practice of the Department of Laboratory Medicine (University of Debrecen). Serum or plasma samples were used for determining measures descriptive of carbohydrate homeostasis (glucose, insulin, hemoglobin A1c [HgA1c]), lipid homeostasis (total cholesterol, triglyceride, low-density lipoprotein [LDL]cholesterol, high-density lipoprotein [HDL]-cholesterol, lipoprotein(a), apolipoprotein A1 [ApoA1], apolipoprotein $\mathrm{B}[\mathrm{ApoB}]$ ), metabolism of L-arginine (folic acid, vitamin B12, urea), kidney function (glomerular filtration rate, urea, creatinine), liver function (glutamate-oxaloacetate transaminase, glutamate-pyruvate transaminase, gammaglutamyltransferase), status of skeletal muscles (creatine kinase [CK], lactate dehydrogenase), and systemic inflammation (C-reactive protein [CRP], procalcitonin, fibrinogen). In addition to the use of serum CRP concentration, patients 
were dichotomized as having high vs normal CRP level with the cutoff being $4.6 \mathrm{mg} / \mathrm{L}$ and $5.2 \mathrm{mg} / \mathrm{L}$ for female and male patients, respectively (these are the reference values used in routine clinical practice by the Department of Laboratory Medicine, University of Debrecen). Serum samples used to determine L-arginine, ADMA, and symmetric dimethylarginine (SDMA) were frozen within $60 \mathrm{~min}$ and stored at $-80^{\circ} \mathrm{C}$ until further analysis.

\section{Determination of ADMA and other arginine derivatives}

Arginine and its derivatives were measured as previously. ${ }^{26,27}$ Briefly, $250 \mu \mathrm{L}$ of serum was mixed with the internal standard $(50 \mu \mathrm{L}$ of $1,000 \mu \mathrm{mol} / \mathrm{L} \mathrm{L}$-homoarginine hydrochloride from Sigma-Aldrich Co., St Louis, MO, USA) and borate buffer $(700 \mu \mathrm{L}, \mathrm{pH} 9.0)$. This mixture was passed through solid-phase extraction cartridges (OASIS MCX 3cc) applying a 12-column manifold (J.T. Baker, Phillipsburg, NJ, USA). After successive washing with borate buffer ( $\mathrm{pH} 9.0$ ), deionized water, and methanol (Scharlau, Sentmenat, Spain), the sample (containing the arginine derivatives) was eluted with $1 \mathrm{~mL}$ of ammonia-water-methanol solution (10/40/50, v/v/v) (Reanal, Budapest, Hungary). The solvent was evaporated in vacuum under nitrogen atmosphere to dryness at $60^{\circ} \mathrm{C}$, and then the residue was dissolved in $200 \mu \mathrm{L}$ of deionized water. This solution was used for derivatization.

For derivatization, the sample $(200 \mu \mathrm{L})$ was mixed with $63 \mu \mathrm{L}$ of ortho-phthaldialdehyde/3-mercaptopropionic acid fluorescent reagent solution, incubated at $22^{\circ} \mathrm{C}$ for $10 \mathrm{~min}$, and then kept at $5^{\circ} \mathrm{C}$ until the measurements. Chromatographic system of a Waters 2695 Separations Module equipped with thermostable autosampler $\left(5^{\circ} \mathrm{C}\right)$ and column module $\left(35^{\circ} \mathrm{C}\right)$, a Waters 2745 Fluorescence Detector (Waters, Milford, MA, USA), and a C-18 $(4.6 \times 150 \mathrm{~mm}, 3.5 \mu \mathrm{m})$ column were used for analysis. A sample $(10 \mu \mathrm{L})$ was injected into the chromatographic system. Gradient elution at $1 \mathrm{~mL} / \mathrm{min}$ flow rate was applied using mobile phase $\mathrm{A}\left(20 \mathrm{mmol} / \mathrm{L}\right.$ of $\left(\mathrm{NH}_{4}\right)_{2} \mathrm{CO}_{3}$ in water, $\mathrm{pH}$ adjusted to $7.5 \pm 0.05$ with formic acid) and mobile phase $\mathrm{B}$ (acetonitrile). The gradient condition was as follows: 0-13 min: 91\% A and 9\% B; 13-15 min: linear change to $70 \% \mathrm{~A}$ and $30 \% \mathrm{~B}$ holding this setting for additional $5 \mathrm{~min}$; and 20-20.1 min: linear change to $91 \% \mathrm{~A}$ and $9 \% \mathrm{~B}$ holding this for $35 \mathrm{~min}$.

Analytes were detected at $\lambda_{\mathrm{ex}}=337 \mathrm{~nm}$, while $\lambda_{\mathrm{em}}=520 \mathrm{~nm}$ was used for arginine and homoarginine and $\lambda_{\mathrm{em}}=454 \mathrm{~nm}$ for ADMA and SDMA.

\section{St George's Respiratory Questionnaire}

The official Hungarian version of SGRQ, validated for a 1-month recall period reflective of the patients' recollection of their symptoms, was used according to the SGRQ manual supplied by the proprietor. ${ }^{28}$ SGRQ quantifies health impairment with three component scores and one total score. The Symptoms score describes the effect, frequency, and severity of respiratory symptoms based on the patients' perception of their recent respiratory problems; Activity score quantifies the impairment in the daily physical activity; Impacts score includes a wide array of disturbances related to the psychosocial function; and the Total score sums up the significance of the disease on overall health status. All scores are expressed as a percentage, with $100 \%$ representing the worst and $0 \%$ indicating the best subjective health status. Differences in scores were considered clinically meaningful if they exceeded $4 \%$ points. ${ }^{29}$ The questionnaire was selfadministered under supervision. Data entry was performed by two independent raters who diligently followed the data entry guidelines. Interrater variability assessed by Spearman's correlation was 0.99 ( $P<0.001), 0.988$ ( $P<0.001), 0.999$ $(P<0.001)$, and $0.999(P<0.001)$ for the Symptoms, Activity, Impacts, and Total scores, respectively. The mean of scores provided by the two raters was used for statistical analysis.

To assess the extent of symptom control, data were dichotomized with respect to the Symptoms score component. Patients with a Symptoms score $<32.66 \%$ were put in the better-controlled group, while patients with a Symptoms score $\geq 32.66 \%$ formed the worse-controlled group (32.66\% was the median Symptoms score of the whole cohort). This dichotomization was used for stratification of the final multiple regression model.

\section{Statistical analysis}

Normality of continuous variables was checked by the Shapiro-Wilk test. In case of Gaussian distribution, Student's $t$-test was used for the comparison of two data sets; if not, Mann-Whitney $U$ test was carried out. Frequencies were compared using Pearson's $\chi^{2}$ test.

Demographic, anthropometric, anamnestic, laboratory, and SGRQ data were divided into two groups with lower and higher $\mathrm{R}_{\mathrm{aw}}$ (using the median value of $\mathrm{R}_{\mathrm{aw}}$ as a cutoff level) for comparison. Thus, patients with $\mathrm{R}_{\text {aw }}<0.27 \mathrm{kPa} \cdot \mathrm{s} / \mathrm{L}$ formed the lower $\mathrm{R}_{\mathrm{aw}}$ group ( $\left.\mathrm{n}=34\right)$, while the higher $\mathrm{R}_{\mathrm{aw}}$ group ( $n=40$ ) contained patients with $R_{a w} \geq 0.27 \mathrm{kPa} \cdot \mathrm{s} / \mathrm{L}$. In addition, demographic, anthropometric, pulmonary function, and SGRQ data were compared in terms of symptom control achieved in our cohort (herein $n=73$; SGRQ data were 
missing for one patient). Dichotomy of patients based on the median of Symptoms scores as a cutoff level provided a bettercontrolled $(<32.66)$ group $(n=37)$ and a worse-controlled $(\geq 32.66)$ one $(n=36)$ (loss of one patient in this approach was due to the lack of the SGRQ result for this patient).

The relationship between $\mathrm{R}_{\mathrm{aw}}$ and serum ADMA level was investigated with Pearson's correlation as well as with simple and multiple linear regression. To ensure normal distribution of variables for these analyses, CK, total cholesterol, LDL-cholesterol, HDL-cholesterol, ApoA1, ApoB, insulin, $\mathrm{HgA} 1 \mathrm{c}$, folate, thyroid-stimulating hormone (sensitive), ADMA, homeostatic model assessment index, $\mathrm{R}_{\mathrm{aw}}, \mathrm{FEF}_{25-75 \%}, \mathrm{RV}$, and $\mathrm{RV} \%$ pred were log-transformed, and reciprocal of square of glucose concentration was computed.

To identify determinants of $\mathrm{R}_{\mathrm{aw}}$ as well as ADMA, simple linear regression was carried out including traditional confounding factors (age, gender, height, disease duration in years), lung function parameters, laboratory parameters characteristic of carbohydrate, lipid, and arginine homeostasis, hepatic, kidney, and skeletal muscle function, and furthermore, systemic markers of inflammation. Missing data were omitted. Then, in order to eliminate effects of potential confounders, multiple linear regression modeling was performed including all significant regressors determined with the simple linear regression as well as age and gender (as a priori variables). Inclusion of the defined daily dose of steroids into the initial model should be noted. Variables were introduced into the initial multiple model simultaneously, and then factors not contributing significantly to the model were deleted. In addition, the final model was stratified with respect to the better or worse symptom control dichotomized by the median of Symptoms scores of SGRQ. Heteroskedasticity and goodness of fit for the model were assessed by CookWeisberg and Ramsey test.

Statistical analysis was performed with Stata 13.0 software (Stata Corporation). Values are given as mean \pm standard deviation (SD) or median (with the interquartile range $[\mathrm{IQR}]$ ), and regression coefficients are presented with their $95 \%$ confidence interval (CI).

\section{Results \\ Patients}

Of the 74 COPD patients involved in the present study, two were treatment-naïve at the time of inclusion. Overall, 64 patients received inhaled anticholinergics either alone $(n=63)$ or in fixed combination with a beta adrenoceptor agonist (ipratropium with fenoterol) $(n=6)$. Furthermore, 60 patients received inhaled corticosteroids in fixed combination with long-acting beta agonists. Overall, 24 patients received inhaled short-acting beta agonists, and three patients received inhaled long-acting beta agonists as a monotherapy. Other medications included oral use of methylxanthines $(n=30)$ and montelukast $(\mathrm{n}=3)$.

\section{Comparison of patients with lower and higher airflow resistance}

The two groups, dichotomized with respect to the median of $\mathrm{R}_{\mathrm{aw}}$ values, were proved to be homogenous regarding most of the parameters investigated. However, the average of patient's age was moderately higher, while the average of years of smoking, pack-years, and all SGRQ scores was substantially higher in the patient group with higher $\mathrm{R}_{\text {aw }}$. Nevertheless, there was no significant difference in the prevalence of smoking at the time of the investigation. The height of patients was slightly but statistically significantly smaller in the higher $\mathrm{R}_{\mathrm{aw}}$ group. Although the median of CRP level among patients with higher $\mathrm{R}_{\mathrm{aw}}$ was only on the verge of statistical significance $(P=0.052)$, frequency of elevated CRP was significantly greater in the higher $\mathrm{R}_{\mathrm{aw}}$ group than in the lower $\mathrm{R}_{\text {aw }}$ group (Table 1).

\section{Comparison of the better-controlled and worse-controlled patients}

Demographic and anthropometric parameters did not differ significantly when the patient cohort was compared across level of disease control (better-controlled vs worse-controlled) (Table 2). Lung function parameters describing the flow in the airways and $\mathrm{G}_{\mathrm{aw}}$ were significantly lower in the worsecontrolled group. Consistent with this, TGV\% pred, RV\% pred, $\mathrm{RV} / \mathrm{TLC} \%$ pred, and $\mathrm{R}_{\mathrm{aw}}$ were significantly higher among patients in the worse-controlled group. All SGRQ scores were substantially higher in the worse-controlled group (showing greater health impairment and poorer quality of life) (Table 2).

\section{Significant predictors of $R_{a w}$ and serum ADMA concentration}

The median serum ADMA levels were practically the same in all patient groups, that is, 0.58 (IQR: $0.44-0.67) \mu \mathrm{mol} / \mathrm{L}, 0.58$ (IQR: $0.43-0.64) \mu \mathrm{mol} / \mathrm{L}$, and 0.58 (IQR: 0.46-0.7) $\mu \mathrm{mol} / \mathrm{L}$ in the whole data set and in strata of patients with lower and higher $\mathrm{R}_{\mathrm{aw}}$, respectively. Upon assessing the linear relationship between $\log \mathrm{R}_{\mathrm{aw}}$ and $\log$ ADMA, we found significant positive correlation in the whole data set (Figure 2) and in the worse-controlled stratum (Pearson's correlation 
Table I Characteristics of the whole population of COPD patients $(n=74)$ and of its two groups containing patients with lower $(n=34)$ and higher $(n=40) R_{a w}$ values

\begin{tabular}{|c|c|c|c|c|}
\hline Parameters & Whole population & Lower $\mathbf{R}_{\mathrm{aw}}$ & Higher $\mathbf{R}_{\mathrm{aw}}$ & $P$-value \\
\hline Age (years) & $62.15 \pm 9.70$ & $59.53 \pm 7.92$ & $64.38 \pm 10.58$ & 0.031 \\
\hline Gender (female/male) & $27 / 47$ & $12 / 22$ & $15 / 25$ & 0.844 \\
\hline Smoker (no/yes) & $49 / 25$ & $23 / 11$ & $26 / 14$ & 0.810 \\
\hline Smoking (pack-years) & $20.00(5.25-33.75)$ & $17.50(2.25-25.00)$ & $26.68(8.38-39.40)$ & 0.035 \\
\hline Smoking (years) & $10.00(0.00-33.00)$ & $0.50(0.00-20.00)$ & $20.00(0.00-40.00)$ & 0.031 \\
\hline Diabetes (no/yes) & $61 / 13$ & $29 / 5$ & $32 / 8$ & 0.551 \\
\hline Dyslipidemia (no/yes) & $48 / 26$ & $23 / 11$ & $25 / 15$ & 0.644 \\
\hline RR systolic (mmHg) & $136.49 \pm 15.85$ & $134.18 \pm \mid 4.65$ & $138.45 \pm 16.74$ & 0.251 \\
\hline $\mathrm{RR}$ diastolic $(\mathrm{mmHg})$ & $82.38 \pm 14.06$ & $80.85 \pm 15.24$ & $83.68 \pm 13.04$ & 0.393 \\
\hline Hypertension (no/yes) & $31 / 43$ & $18 / 16$ & $13 / 27$ & 0.076 \\
\hline AMI (no/yes) & $65 / 9$ & $29 / 5$ & $36 / 4$ & 0.537 \\
\hline Stroke (no/yes) & $73 / 1$ & $33 / 1$ & $40 / 0$ & 0.275 \\
\hline Disease duration (years) & $5.00(3.00-10.00)$ & $5.50(3.00-10.00)$ & $5.00(3.00-9.00)$ & 0.798 \\
\hline Waist (cm) & $101.99 \pm 14.31$ & $|02.25 \pm| 4.0 \mid$ & $101.78 \pm \mid 4.74$ & 0.888 \\
\hline Weight (kg) & $79.71 \pm 17.12$ & $81.55 \pm 17.44$ & $78.15 \pm 16.92$ & 0.406 \\
\hline Height (m) & $1.68 \pm 0.094$ & $1.7 I \pm 0.086$ & $|.65 \pm 0.09|$ & 0.003 \\
\hline BMI $\left(\mathrm{kg} / \mathrm{m}^{2}\right)$ & $28.19 \pm 5.09$ & $27.6 I \pm 4.94$ & $28.68 \pm 5.23$ & 0.380 \\
\hline ADMA $(\mu \mathrm{mol} / \mathrm{L})$ & $0.58(0.44-0.67)$ & $0.58(0.43-0.64)$ & $0.58(0.46-0.70)$ & 0.354 \\
\hline SDMA ( $\mu \mathrm{mol} / \mathrm{L})$ & $0.48(0.42-0.58)$ & $0.49(0.42-0.57)$ & $0.48(0.4 \mathrm{I}-0.62)$ & 0.425 \\
\hline L-Arginine ( $\mu \mathrm{mol} / \mathrm{L})$ & $|04.20 \pm 28.8|$ & $|07.70 \pm 28.7|$ & $101.23 \pm 28.92$ & 0.339 \\
\hline $\mathrm{B} \mid 2$ (pmol/L) & $302.40(237.70-348.50)$ & $308.00(243.10-347.30)$ & $288.75(224.35-348.65)$ & 0.498 \\
\hline Folate $(\mathrm{nmol} / \mathrm{L})$ & 17.85 (I3.74-23.47) & $18.49(|4.9|-23.86)$ & I6.92 (|2.7|-22.84) & 0.293 \\
\hline Urea $(\mathrm{mmol} / \mathrm{L})$ & $5.3 \mathrm{I} \pm \mathrm{I} .37$ & $5.37 \pm 1.35$ & $5.26 \pm 1.40$ & 0.731 \\
\hline Creatinine $(\mu \mathrm{mol} / \mathrm{L})$ & $71.00(61.00-81.00)$ & $70.50(58.00-90.00)$ & $73.50(61.00-79.00)$ & 0.576 \\
\hline GFR $\left(\mathrm{mL} / \mathrm{min} / \mathrm{l} .73 \mathrm{~m}^{2}\right)$ & 91.00 (80.00-91.00) & $88.50(80.00-91.00)$ & 91.00 (80.50-91.00) & 0.677 \\
\hline GOT (U/L) & $19.50(15.00-23.00)$ & $20.50(16.00-23.00)$ & $19.00(14.00-23.00)$ & 0.254 \\
\hline GPT (U/L) & $18.00(14.00-24.00)$ & $20.00(13.00-26.00)$ & $18.00(15.00-24.00)$ & 0.490 \\
\hline$\gamma \mathrm{GT}(\mathrm{U} / \mathrm{L})$ & $32.50(20.00-49.00)$ & $31.00(20.00-49.00)$ & $33.00(19.50-47.00)$ & 0.991 \\
\hline CK (U/L) & $101.00(74.00-139.00)$ & $106.00(74.00-165.00)$ & $99.00(76.00-135.50)$ & 0.591 \\
\hline $\mathrm{LDH}(\mathrm{U} / \mathrm{L})$ & $208.62 \pm 34.98$ & $204.15 \pm 36.82$ & $212.43 \pm 33.32$ & 0.314 \\
\hline Glucose (mmol/L) & $5.00(4.20-5.80)$ & $5.00(4.00-5.60)$ & $5.10(4.60-6.25)$ & 0.462 \\
\hline Insulin (mU/L) & $8.95(5.55-16.50)$ & $10.15(5.65-15.35)$ & $7.80(5.25-19.85)$ & 0.892 \\
\hline $\mathrm{HgAlc}(\%)$ & $5.70(5.50-6.10)$ & $5.60(5.40-6.10)$ & $5.80(5.50-6.20)$ & 0.295 \\
\hline HOMA & $2.14(1.14-4.67)$ & $2.14(1.23-3.64)$ & $2.15(1.05-5.21)$ & 0.910 \\
\hline Cholesterol (mmol/L) & $5.30(4.00-6.30)$ & $5.60(5.00-6.30)$ & $5.00(4.00-6.15)$ & 0.159 \\
\hline LDL-C (mmol/L) & $3.10(2.60-3.70)$ & $3.20(2.60-3.80)$ & $2.85(2.4-3.65)$ & 0.116 \\
\hline $\mathrm{HDL}-\mathrm{C}(\mathrm{mmol} / \mathrm{L})$ & I.40 (I.20-I.80) & $1.45(1.20-1.80)$ & $1.40(1.10-1.80)$ & 0.752 \\
\hline ApoAI $(g / L)$ & $1.55(1.38-1.80)$ & $1.61(1.47-1.76)$ & $1.52(1.33-1.85)$ & 0.365 \\
\hline ApoB (g/L) & $1.00(0.85-1.28)$ & $1.00(0.91-1.28)$ & $0.95(0.83-1.19)$ & 0.219 \\
\hline $\operatorname{Lp}(\mathrm{a})(\mathrm{mg} / \mathrm{L})$ & $129.50(58.00-455.00)$ & $136.00(38.00-568.00)$ & $106.50(59.50-363.50)$ & 0.991 \\
\hline $\mathrm{TG}(\mathrm{mmol} / \mathrm{L})$ & $1.35(1.00-2.00)$ & $1.70(1.00-2.00)$ & $1.20(0.90-1.85)$ & 0.256 \\
\hline $\mathrm{CRP}(\mathrm{mg} / \mathrm{L})$ & $2.00(1.210-4.00)$ & $1.85(1.210-3.10)$ & $2.80(1.25-6.65)$ & 0.052 \\
\hline CRP (normal/high) & $58 / 16$ & $31 / 3$ & $27 / 13$ & 0.014 \\
\hline Fibrinogen (g/L) & $3.67(3.25-4.00)$ & $3.56(3.12-4.03)$ & $3.77(3.35-4.00)$ & 0.282 \\
\hline Procalcitonin $(\mu g / L)$ & $0.00(0.00-0.00)$ & $0.00(0.00-0.00)$ & $0.00(0.00-0.00)$ & 0.278 \\
\hline sTSH (mU/L) & $1.26(0.84-1.93)$ & $1.30(0.76-2.16)$ & $1.21(0.84-1.67)$ & 0.558 \\
\hline SGRQ Symptoms score & 32.66 (I3.64-58.28) & $25.55(8.28-36.98)$ & $40.46(21.54-68.19)$ & $\underline{0.004}$ \\
\hline SGRQ Impacts score & 29.64 (I5.44-49.79) & $20.85(11.00-38.70)$ & $36.58(22.20-52.67)$ & $\underline{0.011}$ \\
\hline SGRQ Activity score & $57.32(47.24-72.08)$ & $53.25(23.4 I-66.09)$ & 65.39 (53.57-72.9I) & $\underline{0.008}$ \\
\hline SGRQ Total score & $41.08 \pm 20.99$ & $33.82 \pm 21.46$ & $47.07 \pm|8.8|$ & $\underline{0.006}$ \\
\hline
\end{tabular}

Notes: Patients with $R_{a w}<0.27 \mathrm{kPa} \cdot \mathrm{s} / \mathrm{L}$ formed the lower $\mathrm{R}_{\mathrm{aw}}$ group, while patients with $\mathrm{R}_{\mathrm{aw}} \geq 0.27 \mathrm{kPa} \cdot \mathrm{s} / \mathrm{L}$ were put in the higher $\mathrm{R}_{\mathrm{aw}}$ group ( $0.27 \mathrm{kPa} \cdot \mathrm{s} / \mathrm{L}$ was the median $\mathrm{R}_{\mathrm{aw}}$ of the whole cohort). Data are presented as mean $\pm \mathrm{SD}$ or median (interquartile range) unless otherwise stated. Differences between the two groups were considered significant at $P<0.05$ (indicated in bold). Clinically meaningful differences of SGRQ results are underlined.

Abbreviations: $\mathrm{R}_{\mathrm{aw}}$, airway resistance; $\mathrm{RR}$, blood pressure (measured according to Riva-Rocci); AMl, acute myocardial infarction; BMI, body mass index; $A$ DMA, asymmetric dimethylarginine; SDMA, symmetric dimethylarginine; GFR, glomerular filtration rate; GOT, glutamate-oxaloacetate transaminase; GPT, glutamate-pyruvate transaminase;

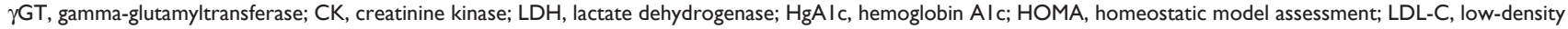
lipoprotein-cholesterol; HDL-C, high-density lipoprotein-cholesterol; ApoAI, apolipoprotein AI; ApoB, apolipoprotein B; Lp(a), lipoprotein(a); TG, triglyceride; CRP, C-reactive protein; sTSH, thyroid-stimulating hormone-sensitive; SGRQ, St George's Respiratory Questionnaire; SD, standard deviation. 
Table 2 Main characteristics of the whole population of COPD patients (having complete SGRQ data; $n=73$ ) and of its bettercontrolled $(n=37)$ and worse-controlled $(n=36)$ groups

\begin{tabular}{|c|c|c|c|c|}
\hline Parameters & Whole population & Better-controlled & Worse-controlled & $P$-value \\
\hline \multicolumn{5}{|c|}{ Demographic and anthropometric parameters } \\
\hline Age (years) & $62.01 \pm 9.70$ & $61.32 \pm 8.35$ & $62.72 \pm 10.99$ & 0.542 \\
\hline Gender (female/male) & $27 / 46$ & $13 / 24$ & $14 / 22$ & 0.740 \\
\hline Height (m) & $1.68 \pm 0.09$ & $1.70 \pm 0.10$ & $1.66 \pm 0.08$ & 0.083 \\
\hline Weight (kg) & $79.61 \pm 17.22$ & $82.36 \pm 18.65$ & $76.77 \pm 15.37$ & 0.173 \\
\hline \multicolumn{5}{|c|}{ Lung function test parameters } \\
\hline FVC\% pred & $82.30 \pm 17.44$ & $87.46 \pm 16.58$ & $77.00 \pm 16.90$ & 0.009 \\
\hline IVC\% pred & $87.00(74.00-100.00)$ & $89.00(78.00-100.00)$ & $85.00(70.00-99.50)$ & 0.166 \\
\hline TLC\% pred & $113.00(103.00-127.00)$ & $108.00(101.00-120.00)$ & $121.50(106.50-130.00)$ & 0.086 \\
\hline TGV\% pred & 140.00 (|23.00-167.00) & 135.00 (| | $6.00-\mid 55.00)$ & I57.00 (I26.50-I78.50) & 0.025 \\
\hline RV\% pred & $172.03 \pm 47.23$ & $157.14 \pm 35.80$ & $187.33 \pm 52.87$ & 0.006 \\
\hline RV/TLC\% pred & $140.47 \pm 20.99$ & $|32.00 \pm| 6.7 \mid$ & $149.17 \pm 2 \mid .57$ & $<0.001$ \\
\hline FEV $\%$ pred & $66.08 \pm 20.04$ & $74.19 \pm 16.98$ & $57.75 \pm 19.71$ & $<\mathbf{0 . 0 0 1}$ \\
\hline PEF\% pred & $52.00(39.00-73.00)$ & $58.00(50.00-77.00)$ & $41.50(29.50-59.50)$ & $<0.001$ \\
\hline $\mathrm{FEF}_{25-75 \%} \%$ pred & $35.00(24.00-53.00)$ & $42.00(29.00-60.00)$ & $28.50(18.50-46.50)$ & 0.006 \\
\hline $\mathrm{MEF}_{50 \%} \%$ pred & $37.00(20.00-58.00)$ & $43.00(32.00-63.00)$ & $24.50(16.00-49.00)$ & $<0.001$ \\
\hline $\mathrm{FEV}_{1} / \mathrm{IVC} \%$ pred & $76.11 \pm 16.36$ & $82.19 \pm 13.36$ & $69.86 \pm 16.96$ & $<0.001$ \\
\hline $\mathrm{FEV} / \mathrm{FVC}$ & $0.65(0.54-0.74)$ & $0.68(0.64-0.76)$ & $0.59(0.48-0.7 I)$ & 0.007 \\
\hline $\mathrm{R}_{\mathrm{aw}}(\mathrm{kPa} \cdot \mathrm{s} / \mathrm{L})$ & $0.27(0.22-0.42)$ & $0.25(0.20-0.31)$ & $0.33(0.26-0.53)$ & 0.008 \\
\hline $\mathrm{G}_{\mathrm{aw}}(\mathrm{L} / \mathrm{kPa} \cdot \mathrm{s})$ & $3.67(2.36-4.64)$ & $3.96(3.27-4.96)$ & $3.07(1.90-3.86)$ & 0.007 \\
\hline \multicolumn{5}{|l|}{ SGRQ } \\
\hline Symptoms score & $32.66(13.64-58.28)$ & I $3.64(5.20-25.55)$ & $60.02(43.24-76.70)$ & $\leq 0.001$ \\
\hline Impacts score & 29.66 (I7.09-49.79) & $|8.5|(\mid 0.10-29.66)$ & 47.01 (3I.34-54.40) & $\leq 0.001$ \\
\hline Activity score & $59.45(47.63-72.08)$ & $52.14(24.62-59.45)$ & $66.4 \mathrm{I}(57.32-82.57)$ & $\leq \mathbf{0 . 0 0 1}$ \\
\hline Total score & $41.08 \pm 20.99$ & $27.61 \pm 15.94$ & $54.93 \pm 15.98$ & $\leq 0.001$ \\
\hline
\end{tabular}

Notes: Patients in the better-controlled group had a Symptoms score smaller than the median Symptoms score (for the whole cohort), while Symptoms score of patients in the worse-controlled group reached or exceeded this median value (32.66 was the median SGRQ Symptoms score of the whole cohort). Data are presented as mean \pm SD or median (interquartile range) unless otherwise stated. Differences between the two groups were considered significant at $P<0.05$ (indicated in bold). Clinically meaningful differences of SGRQ results are underlined. It should be noted that only 73 patients had complete SGRQ results.

Abbreviations: SGRQ, St George's Respiratory Questionnaire; FVC, forced vital capacity; IVC, inspiratory vital capacity; TLC, total lung capacity; TGV, thoracic gas volume; RV, residual volume; $\mathrm{FEV}_{1}$, forced expiratory volume in I s; PEF, peak expiratory flow; $\mathrm{FEF}_{25-75 \%}$, forced expiratory flow between $25 \%$ and $75 \%$ of $\mathrm{FVC}$; $\mathrm{MEF}$, maximal expiratory flow; $\mathrm{R}_{\mathrm{aw}}$, airway resistance; $\mathrm{G}_{\mathrm{aw}}$, airway conductance; $\mathrm{SD}$, standard deviation.

coefficient: 0.25 and $0.35 ; P=0.03$ and $P=0.04$, respectively). However, there was a considerably weaker and statistically nonsignificant correlation in the better-controlled stratum (Pearson's correlation coefficient: $0.08, P=0.61$ ).

In accordance with results of the correlation analysis, simple linear regression (used to identify factors significantly determining $\mathrm{R}_{\mathrm{aw}}$ as well as ADMA) revealed that $\log \mathrm{R}_{\mathrm{aw}}$ and $\log$ ADMA are mutually significant predictors of each other (Table 3). After adjusting for all significant predictors and a priori determinants by means of multiple linear regression, the positive association between $\log \mathrm{R}_{\mathrm{aw}}$ and $\log \mathrm{ADMA}$ remained significant ( $\beta$ : 0.42; CI: $0.06,0.77 ; P=0.022)$ (Table 3 ). This positive association of $\log \mathrm{R}_{\mathrm{aw}}$ with $\log$ ADMA became even more pronounced in the worse-controlled stratum of COPD patients ( $\beta$ : 0.84 ; CI: $0.25,1.43 ; P=0.007$ ), while only a weak and statistically nonsignificant association was present in the better-controlled stratum $(\beta:-0.17$; CI: $-0.61,0.27$; $P=0.45)$. The Cook-Weisberg test showed no heteroskedasticity for the full model, the worse-controlled stratum, and the better-controlled stratum $(P=0.18, P=0.74$, and $P=0.39$, respectively). Furthermore, all three models showed good fit reflected by the locally weighted scatterplot smoothing (Figure 3 ) as well as by the Ramsey test $(P=0.75, P=0.67$, and $P=0.15$ for the whole data set, the worse-controlled stratum, and the better-controlled stratum, respectively).

In addition, the final multiple linear regression model (built for $\mathrm{R}_{\mathrm{aw}}$ ) indicated that presence of elevated CRP confers significant impact on COPD (ie, elevated CRP is associated with higher $\mathrm{R}_{\text {aw }}$. We also found that $\log \mathrm{FEF}_{25-75 \%}$ $\%$ pred, the lung function parameter descriptive of small airway dysfunction, showed negative association with $\log \mathrm{R}_{\mathrm{aw}}(\beta:-0.33$; CI: $-0.51,-0.15 ; P<0.001)$ (Table 3$)$. Consistent with this latter finding, there was a strong significant positive correlation between $\log \mathrm{G}_{\mathrm{aw}}$ and $\log$ $\mathrm{FEF}_{25-75 \%} \%$ pred in the whole sample, in the worse-controlled stratum and in the better-controlled stratum too (Pearson's correlation coefficient: $0.53,0.40$, and $0.57 ; P<0.001$, $P=0.017$, and $P<0.001$, respectively). 


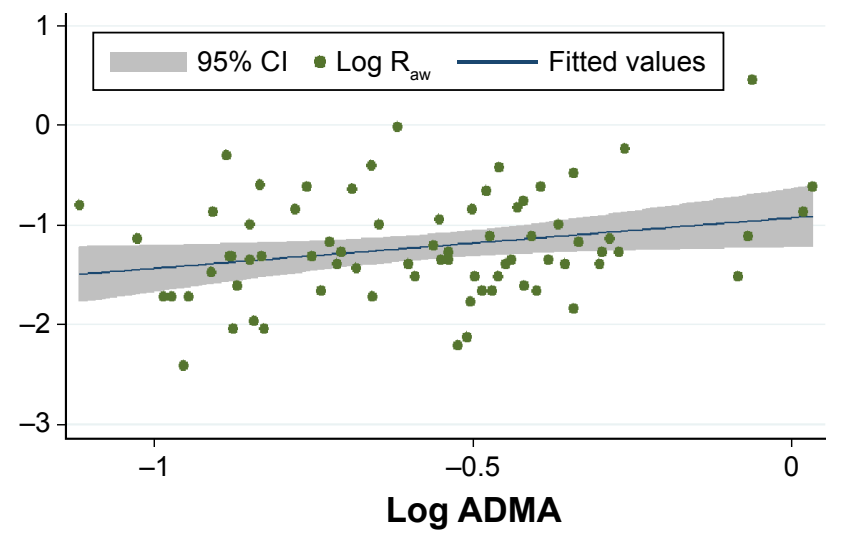

Figure 2 Correlation of (log transformed values of) $R_{a w}$ and serum concentration of ADMA in the whole data set $(n=74)$.

Notes: The $x$-axis shows the common logarithm of serum ADMA concentration (in $\mu \mathrm{mol} / \mathrm{L}$ ), while the $y$-axis denotes the common logarithm of $R_{\text {aw }}$ (in $\mathrm{kPa} \cdot \mathrm{s} / \mathrm{L}$ ). The blue line shows the fitted values of log ADMA and log $R_{a w}$ data pairs (represented by the green dots), while the gray zone indicates the $95 \% \mathrm{Cl}$.

Abbreviations: $R_{a w}$, airway resistance; ADMA, asymmetric dimethylarginine; $\mathrm{Cl}$, confidence interval.

Furthermore, all SGRQ scores (including the Total score) showed clinically meaningful differences with respect to the extent of airflow limitation (lower $\mathrm{R}_{\mathrm{aw}}$ group vs higher $\mathrm{R}_{\mathrm{aw}}$ group) as well as symptom control (worse-controlled stratum vs better-controlled stratum). Moreover, the Total score showed significant negative correlation with $\mathrm{FEV}_{1} \%$ pred (Pearson's correlation coefficient: $-0.43, P<0.001$ ).

\section{Discussion}

The major finding of our study is that serum ADMA level of COPD patients shows significant positive correlation with airflow limitation indicated by $\mathrm{R}_{\mathrm{aw}}$. Due to the numerous confounders, inherent of a clinically diverse population, multiple linear regression modeling was implemented. We found that the said strong positive correlation remained significant after the elimination of confounders. We identified two other influential parameters concerning airflow limitation: CRP, a serum marker of systemic inflammation, and FEF25-75\% $\%$ pred, a dynamic pulmonary function parameter describing the function of small airways. ${ }^{30}$

CRP is an acute-phase reactant that is known as a stable biomarker for systemic inflammation. ${ }^{31}$ Analysis of the Lung Health Study with 4803 participants suffering from mild-to-moderate COPD concluded that serum CRP level is a significant predictor of future risk of death and cardiovascular events in COPD, and it affords additional information beyond knowledge provided by traditional measures such as $\mathrm{FEV}_{1}$ and smoking habits. ${ }^{32}$ The clinical relevance of elevated CRP is undisputed, with serum levels above $1 \mathrm{mg} / \mathrm{L}$ being indicative of increased cardiovascular risk in healthy
Table 3 Significant predictors of ADMA serum level and $R_{a w}$ determined with simple and multiple (for $R_{a w}$ only) linear regression for the whole population of COPD patients $(n=74)$

\begin{tabular}{|c|c|c|}
\hline Parameters & Coefficient $(95 \% \mathrm{Cl})$ & $P$-value \\
\hline \multicolumn{3}{|c|}{ Simple linear regression of ADMA (log transformed) } \\
\hline Smoker & $0.13(0.006,0.26)$ & 0.039 \\
\hline Log SDMA & $1.28(0.93,1.63)$ & $<0.001$ \\
\hline Fibrinogen & $0.11(0.034,0.19)$ & 0.006 \\
\hline $\log R_{a w}$ & $0.13(0.012,0.24)$ & 0.030 \\
\hline \multicolumn{3}{|c|}{ Simple linear regression of $R_{a w}$ (log transformed) } \\
\hline Age & $0.019(0.0076,0.03 \mathrm{I})$ & 0.002 \\
\hline Height & $-1.72(-2.97,-0.47)$ & 0.008 \\
\hline Uric acid & $0.0017(0.00050,0.0029)$ & 0.006 \\
\hline Fibrinogen & $0.18(0.014,0.34)$ & 0.034 \\
\hline CRP (normal/high) & $0.61(0.35,0.87)$ & $<0.001$ \\
\hline Log ADMA & $0.5 \mathrm{I}(0.049,0.96)$ & 0.030 \\
\hline SDMA & $0.94(0.032,1.85)$ & 0.043 \\
\hline FVC & $-0.32(-0.44,-0.19)$ & $<0.001$ \\
\hline FVC\% pred & $-0.0087(-0.015,-0.0020)$ & 0.012 \\
\hline $\mathrm{FEV}_{\text {, }}$ & $-0.42(-0.56,-0.28)$ & $<0.001$ \\
\hline $\mathrm{FEV}_{1} \%$ pred & $-0.011(-0.016,-0.0051)$ & $<0.001$ \\
\hline $\mathrm{FEV}_{1} / \mathrm{FVC}$ & $-0.015(-0.024,-0.0059)$ & 0.002 \\
\hline $\mathrm{FEF}_{25-75 \%}$ & $-0.38(-0.50,-0.25)$ & $<0.001$ \\
\hline Log $\mathrm{FEF}_{25-75 \%} \%$ pred & $-0.49(-0.68,-0.31)$ & $<0.001$ \\
\hline $\mathrm{RV} / \mathrm{TLC} \%$ & $0.024(0.013,0.035)$ & $<0.001$ \\
\hline RV/TLC\% pred & $0.0080(0.0025,0.013)$ & 0.005 \\
\hline IC/TLC & $-2.22(-3.45,-0.98)$ & 0.001 \\
\hline Corticosteroid use & $0.31(0.023,0.60)$ & 0.035 \\
\hline SGRQ Symptoms score & $0.0042(-0.000083,0.0086)$ & 0.054 \\
\hline SGRQ Activity score & $0.0063(0.0014,0.011)$ & 0.012 \\
\hline SGRQ Impacts score & $0.0055(-0.00023,0.011)$ & 0.060 \\
\hline SGRQ Total score & $0.0060(0.00033,0.012)$ & 0.038 \\
\hline \multicolumn{3}{|c|}{ Multiple linear regression of $R_{a w}$ (log transformed) } \\
\hline Log ADMA & $0.42(0.062-0.77 \mathrm{I})$ & 0.022 \\
\hline Log $\mathrm{FEF}_{25-75 \%} \%$ pred & $-0.336(-0.517,-0.154)$ & $<0.001$ \\
\hline CRP (normal/high) & $0.489(0.266,0.713)$ & $<0.001$ \\
\hline
\end{tabular}

Notes: The Symptoms and Impacts scores are also included, although these are on the verge of significance. Regression coefficient values are presented with their 95\% Cls. The initial model for the multiple regression analysis consisted of the significant parameters provided by the simple regression and the relevant a priori identified parameters (the latter ones were omitted from the present table as they did not contribute significantly to the final model). Bold represents statistically significant values.

Abbreviations: ADMA, asymmetric dimethylarginine; $R_{a w}$, airway resistance; $\mathrm{Cl}$, confidence interval; SDMA, symmetric dimethylarginine; CRP, C-reactive protein; FVC, forced vital capacity; $\mathrm{FEV}_{1}$, forced expiratory volume in I s; $\mathrm{FEF}_{25-75 \%}$, forced expiratory flow between $25 \%$ and $75 \%$ of FVC; RV, residual volume; TLC, total lung capacity; IC, inspiratory capacity; SGRQ, St George's Respiratory Questionnaire.

individuals. ${ }^{31}$ In our patient cohort, the serum CRP level was an independent predictor of $\mathrm{R}_{\mathrm{aw}}$, and it remained significant even after the multiple linear regression (Table 3). Moreover, CRP proved to be significant in both strata of multiple linear regression (ie, worse-controlled and better-controlled groups). These results underline the fundamental role of inflammation in the evolution of COPD. It is worthy to note that the effect of elevated CRP was not influenced by the use 


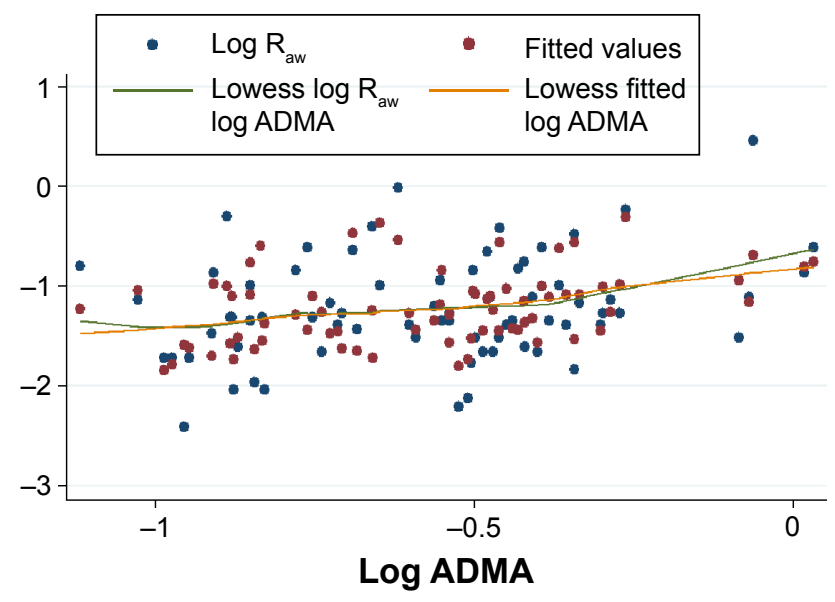

Figure 3 The model describing the correlation between (log transformed values of) $R_{a w}$ and serum concentration of ADMA in the whole data set $(n=74)$.

Notes: The $x$-axis shows the common logarithm of serum ADMA concentration (in $\mu \mathrm{mol} / \mathrm{L}$ ), while the $y$-axis denotes the common logarithm of $R_{2 w}$ (in $\mathrm{kPa} \cdot \mathrm{s} / \mathrm{L}$ ). The blue and red dots indicate the raw (ie, original) values and fitted values obtained by multiple linear regression, respectively. The green and orange lines indicate the curves fitted to the raw data and to data provided by multiple linear regression. Fitting was done by locally weighted scatterplot smoothing (lowess).

Abbreviations: $R_{a w}$, airway resistance; ADMA, asymmetric dimethylarginine.

of corticosteroids which is reflected by the lack of contribution to the model, leading to the omission of corticosteroid use from the final multiple regression model (Table 3).

Involvement of small airways in COPD is a central phenomenon that is critical regarding the progression of this disease. Infiltration of the wall of small airways with immune cells produces inflammatory exudate and airway wall thickening called remodeling. ${ }^{33}$ Accordingly, our result that $\mathrm{FEF} 25-75 \% \%$ pred was a significant independent predictor of $\mathrm{R}_{\mathrm{aw}}$ (provided by both the simple and multiple linear regression; Table 3) reflects the strong involvement of the small airways in the evolution of airflow limitation in our COPD patient cohort. This finding corroborates the findings of others reporting that increase in resistance of small airways plays a significant role in airflow limitation developed in obstructive airway diseases. ${ }^{34}$

The major finding of the present study is that, in our cohort of COPD patients, there is a pronounced positive association between $\mathrm{R}_{\mathrm{aw}}$ and serum ADMA level (Table 3), the extent of which exhibits an inverse relationship with the level of symptom control (ie, a stronger positive relationship between $\mathrm{R}_{\mathrm{aw}}$ and ADMA accompanies with more severe symptoms according to the patient's self-report). This result was presented by the final model of multiple regression, where data were stratified using the median of SGRQ Symptoms scores (containing information about the perception of symptoms over the preceding 4 weeks by quantifying responses with regard to wheezing, shortness of breath, sputum production, and exacerbations). During the analysis, the significant relationship between $\log \mathrm{R}_{\mathrm{aw}}$ and $\log$ ADMA seen in the whole patient cohort became even stronger in the worse-controlled group of patients, while it became weaker and statistically nonsignificant in the bettercontrolled group. It may also be noted that, in agreement with prior reports, ${ }^{35,36}$ the Total score of SGRQ showed a strong negative relationship with $\mathrm{FEV}_{1} \%$.

Based on the significant positive association between $R_{\text {aw }}$ and ADMA, as well as on the interaction between ADMA's influence on $\mathrm{R}_{\text {aw }}$ and disease severity, we propose that ADMA contributes to the progression of COPD by shunting L-arginine toward the arginase pathway, by inducing uncoupling and competitive inhibition of iNOS (activated by the inflammation) as well as eNOS and nNOS (being active constitutively). As a result, increased polyamine formation producing cellular proliferation and fibrosis ensues parallel to spermine's inhibitory action of the constitutive NOS isoforms. The activity of uncoupled iNOS yields reactive agent formation that, in turn, has the propensity to induce expression of protein arginine methyltransferases (enzymes responsible for demethylation of L-arginine side chains in proteins) and to decrease the expression of dimethylarginine dimethylaminohydrolase (an enzyme responsible for ADMA degradation). These processes lead to a further increase of ADMA levels. Moreover, decrease of NO synthesis will lead to NO deficiency contributing to decreased mucociliary clearance and bactericidal activity, increased smooth muscle cell proliferation, and resultant increase of bronchial tone and hyperresponsiveness (Figure 1).,3,37

Limited number of reports deal with the L-arginineADMA homeostasis in context of COPD. Nonetheless, the ADMA level in our cross-sectional study (0.58 [IQR: $0.44-0.66] \mu \mathrm{mol} / \mathrm{L})$ is comparable with that found by others. In a recent study of elderly patients suffering from COPD, serum ADMA levels did not show significant alteration when compared with age- and gender-matched controls, as ADMA levels were $0.319 \pm 2.87 \mu \mathrm{mol} / \mathrm{L}$ and $0.318 \pm 0.389 \mu \mathrm{mol} / \mathrm{L}$ for COPD and control patients, respectively. ${ }^{4}$ Others reported somewhat higher ADMA levels in COPD (and ACOS): $\left(0.70 \pm 0.35 \mu \mathrm{mol} / \mathrm{L},{ }^{38} 0.766 \pm 0.01 \mu \mathrm{mol} / \mathrm{L},{ }^{3}\right.$ and 0.63 [IQR: $\left.0.57-0.72] \mu \mathrm{mol} / \mathrm{L}^{6}\right)$. Results of the two latter patient groups were contrasted with serum ADMA levels of age-matched control groups $\left(0.479 \pm 0.06 \mu \mathrm{mol} / \mathrm{L}^{3}\right.$ and 0.41 [IQR: $\left.0.38-0.46] \mu \mathrm{mol} / \mathrm{L}^{6}\right)$. It may be argued that these systemic levels are in the range considered to be normal $(0.4-1.0 \mu \mathrm{mol} / \mathrm{L})^{3,4,6,8}$ Regardless, ADMA may assume central importance in the etiopathogenesis of COPD if one 
considers that serum ADMA levels may be considerably lower than the intracellular levels, while ADMA exerts its above-mentioned effects intracellularly. This assumption is corroborated by the finding that lung ADMA concentration is one of the highest in the body, and thus, it is likely that even a small increase in the systemic ADMA level reflects significant changes in the pulmonary compartment, ${ }^{39}$ leading to potentially deleterious effects in the airways and lung parenchyma.

Upon comparing these findings to the results obtained by analyzing the relationship between $\mathrm{R}_{\mathrm{aw}}$ and ADMA in a larger $(n=154)$ cohort of BA patients (Tajti et al, unpublished data, 2017) receiving adequate asthma controller therapy, several conclusions may be drawn. Although the final multiple linear regression model did show significant correlation between $\mathrm{R}_{\mathrm{aw}}$ and ADMA, the correlation coefficient was considerably lower in the BA cohort $(\beta: 0.22 ; \mathrm{CI}: 0.054,0.383 ; P=0.01)$ than in the COPD cohort ( $\beta$ : 0.42; CI: $0.06,0.77 ; P=0.022$ ). Moreover, the final model of BA patients did not contain CRP, a ubiquitous marker of inflammation. These findings apparently corroborate the previous proposition that the nature of inflammation differs in these two chronic inflammatory diseases which is reflected by a distinct cytokine profile. ${ }^{40}$ For example, enhanced activity of nuclear factor (NF)- $\kappa \mathrm{B}$, a corticosteroid-responsive transcriptional factor, ${ }^{41}$ was shown in $\mathrm{BA}^{40}$ In COPD, however, although reports showed that the expression profile of $\mathrm{NF}-\kappa \mathrm{B}$ is altered, its resistance to inhaled corticosteroid therapy was also proposed..$^{42}$ In the case of the BA patients receiving inhaled corticosteroids, we could not detect signs of systemic inflammation; that is CRP, fibrinogen, and procalcitonin levels were in the normal range (Tajti et al, unpublished data, 2017). To explain this finding, we presumed that inhibition of NF- $\mathrm{KB}$ expression with corticosteroid therapy suppressed the induction of iNOS and the consequent abundant peroxynitrite formation. Thus, the effect of ADMA on processes affecting $\mathrm{R}_{\mathrm{aw}}$ was limited to the inhibition of constitutive NOS isoforms that led to NO deficiency and an increased $\mathrm{R}_{\mathrm{aw}}$. In COPD, however, we found evidence of a systemic low-grade inflammation that may induce iNOS in a manner independent of NF- $\kappa B$ activation (increase of interferon- $\gamma$ is known in COPD, and it may induce iNOS by activating a distinct enhancer region $)^{41}$ that leads to enhanced oxidative stress. The resulting peroxynitrite can further increase the activity of arginase ${ }^{43,44}$ that impairs the balance of arginase and NOS pathways as reported by others (Figure 1). ${ }^{6,14}$ These synergistic processes present in COPD all contribute to the evolution of pulmonary inflammation, oxidative stress, airway remodeling, and consequent airflow limitation. This may possibly be reflected by the more pronounced relationship between $\mathrm{R}_{\mathrm{aw}}$ and ADMA.

A possible limitation of the present study is stemming from its cross-sectional design that inherently limits the possibility to draw cause-and-effect conclusions. Meticulous care was taken to overcome this shortcoming by collecting information regarding the possible confounders and using multiple linear regression to correct for them. Lack of postbronchodilator whole-body plethysmography may be further considered as a shortcoming. Nevertheless, this patient population was enrolled in a COPD management program for a median of 5 (IQR: 3-10) years. Accordingly, all patients were receiving some form of bronchodilator therapy and were instructed to take their medications as usual on the morning of the examinations. Therefore, these results should be interpreted as on-treatment result. Furthermore, the current study does not have the means to offer a comprehensive overview of relevant biochemical properties and regulatory processes related to the NOS and arginase pathways of L-arginine. Starting from this, further prospective studies are needed to corroborate the hypothetical notions made based on the results of our current study. Nevertheless, this investigation has several merits like the relatively large clinical patient sample, the use of special tools (whole-body plethysmography enabling direct assessment of $\mathrm{R}_{\mathrm{aw}}$, and SGRQ, a validated disease-specific questionnaire), and furthermore, the stringent data analysis resulting in powerful findings.

\section{Conclusion}

We found a significant positive linear relationship between $\mathrm{R}_{\mathrm{aw}}$ and ADMA in a cohort of COPD patients who had evidence of a persistent low-grade systemic inflammation. The strong correlation between $\mathrm{R}_{\mathrm{aw}}$ and ADMA was even more explicit in the group experiencing worse COPD control leading to more severe symptoms. Based on our results, we proposed that ADMA influences the evolution and progression of COPD. Mechanisms of ADMA's effect on $\mathrm{R}_{\mathrm{aw}}$ in COPD may consist of an increase in oxidative stress mediated by products of uncoupled NOS (especially iNOS upregulated by inflammation), by NO deficiency resulting from a competitive inhibition of NOS, and by an increase of arginase activity leading to fibrosis and airway remodeling.

\section{Acknowledgments}

This study was supported by the University of Debrecen, TÁMOP 4.2.4.A/2-11-1-2012-0001, TÁMOP-4.2.2.A-11/1/ KONV-2012-0045, Scientific Research Grant of the Hungarian 
Foundation for Pulmonology (awarded in 2015), and Hungarian Brain Research Program (KTIA_13_NAP-A-V/2).

\section{Disclosure}

The authors report no conflicts of interest in this work.

\section{References}

1. Mathers CD, Loncar D. Projections of global mortality and burden of disease from 2002 to 2030. PLoS Med. 2006;3(11):e442.

2. Loddenkemper R, Gibson GJ, Sibille Y; European Respiratory Society; European Lung Foundation. European Lung White Book: The First Comprehensive Survey on Respiratory Health in Europe. Sheffield: European Respiratory Society; 2003.

3. Aydin M, Altintas N, Cem Mutlu L, et al. Asymmetric dimethylarginine contributes to airway nitric oxide deficiency in patients with COPD. Clin Respir J. Epub 2015 Jun 16.

4. Costanzo L, Pedone C, Battistoni F, Chiurco D, Santangelo S, Antonelli-Incalzi R. Relationship between FEV1 and arterial stiffness in elderly people with chronic obstructive pulmonary disease. Aging Clin Exp Res. Epub 2016 Mar 21.

5. Barnes PJ. Cellular and molecular mechanisms of chronic obstructive pulmonary disease. Clin Chest Med. 2014;35(1):71-86.

6. Ruzsics I, Nagy L, Keki S, et al. L-arginine pathway in COPD patients with acute exacerbation: a new potential biomarker. COPD. 2016; 13(2):139-145.

7. Pera $T$, Zuidhof AB, Smit M, et al. Arginase inhibition prevents inflammation and remodeling in a guinea pig model of chronic obstructive pulmonary disease. J Pharmacol Exp Ther. 2014;349(2):229-238.

8. Scott JA, Duongh M, Young AW, Subbarao P, Gauvreau GM, Grasemann H. Asymmetric dimethylarginine in chronic obstructive pulmonary disease (ADMA in COPD). Int J Mol Sci. 2014;15(4):6062-6071.

9. Gielis JF, Lin JY, Wingler K, Van Schil PE, Schmidt HH, Moens AL. Pathogenetic role of eNOS uncoupling in cardiopulmonary disorders. Free Radic Biol Med. 2011;50(7):765-776.

10. Ritz T, Trueba AF. Airway nitric oxide and psychological processes in asthma and health: a review. Ann Allergy Asthma Immunol. 2014;112(4): 302-308.

11. Wells SM, Holian A. Asymmetric dimethylarginine induces oxidative and nitrosative stress in murine lung epithelial cells. Am J Respir Cell Mol Biol. 2007;36(5):520-528.

12. Ahmad T, Mabalirajan U, Ghosh B, Agrawal A. Altered asymmetric dimethyl arginine metabolism in allergically inflamed mouse lungs. Am J Respir Cell Mol Biol. 2010;42(1):3-8.

13. Klein E, Weigel J, Buford MC, Holian A, Wells SM. Asymmetric dimethylarginine potentiates lung inflammation in a mouse model of allergic asthma. Am J Physiol Lung Cell Mol Physiol. 2010;299(6): L816-L825.

14. Wells SM, Buford MC, Migliaccio CT, Holian A. Elevated asymmetric dimethylarginine alters lung function and induces collagen deposition in mice. Am J Respir Cell Mol Biol. 2009;40(2):179-188.

15. Reczkowski RS, Ash DE. Rat liver arginase: kinetic mechanism, alternate substrates, and inhibitors. Arch Biochem Biophys. 1994;312(1): 31-37.

16. von Elm E, Altman DG, Egger M, et al. The Strengthening the Reporting of Observational Studies in Epidemiology (STROBE) statement guidelines for reporting observational studies. Prev Med. 2007;45(4): 247-251.

17. Kollégium TS. Az Egészségügyi Minisztérium szakmai irányelve a krónikus obstruktiv légúti betegség (chronic obstructive pulmonary disease-COPD) diagnosztikájáról és kezeléséről (1. módosított változat) [Clinical practice guidelines of the Ministry of Health on diagnosis and management of chronic obstructive pulmonary disease (COPD) (first modified version)]. Magyar Közlöny. 2009;21:3661-3692. Hungarian.
18. Vestbo J, Hurd SS, Agustí AG, et al. Global strategy for the diagnosis, management, and prevention of chronic obstructive pulmonary disease: GOLD executive summary. Am J Respir Crit Care Med. 2013;187(4): 347-365.

19. Celli BR, MacNee W; ATS/ERS Task Force. Standards for the diagnosis and treatment of patients with COPD: a summary of the ATS/ERS position paper. Eur Respir J. 2004;23(6):932-946.

20. Swanney MP, Ruppel G, Enright PL, et al. Using the lower limit of normal for the FEV1/FVC ratio reduces the misclassification of airway obstruction. Thorax. 2008;63(12):1046-1051.

21. Nathell L, Nathell M, Malmberg P, Larsson K. COPD diagnosis related to different guidelines and spirometry techniques. Respir Res. 2007;8:89.

22. Topalovic M, Derom E, Osadnik CR, Troosters T, Decramer M, Janssens W; Belgian Pulmonary Function Study Investigators. Airways resistance and specific conductance for the diagnosis of obstructive airways diseases. Respir Res. 2015;16:88.

23. Meguro M, Barley EA, Spencer S, Jones PW. Development and validation of an improved, COPD-specific version of the St George Respiratory Questionnaire. Chest. 2007;132(2):456-463.

24. Miller MR, Hankinson J, Brusasco V, et al; ATS/ERS Task Force. Standardisation of spirometry. Eur Respir J. 2005;26(2):319-338.

25. Wanger J, Clausen JL, Coates A, et al. Standardisation of the measurement of lung volumes. Eur Respir J. 2005;26(3):511-522.

26. Zsuga J, Torok J, Magyar MT, et al. Serum asymmetric dimethylarginine negatively correlates with intima-media thickness in early-onset atherosclerosis. Cerebrovasc Dis. 2007;23(5-6):388-394.

27. Zsuga J, Török J, Magyar MT, et al. Dimethylarginines at the crossroad of insulin resistance and atherosclerosis. Metabolism. 2007;56(3): 394-399.

28. Jones PW, Quirk FH, Baveystock CM. The St George's respiratory questionnaire. Respir Med. 1991;85 Suppl B:25-31; discussion 33-37.

29. Jones PW. St George's respiratory questionnaire: MCID. COPD. 2005; 2(1):75-79.

30. Contoli M, Bousquet J, Fabbri L, et al. The small airways and distal lung compartment in asthma and COPD: a time for reappraisal. Allergy. 2010;65(2):141-151.

31. Windgassen EB, Funtowicz L, Lunsford TN, Harris LA, Mulvagh SL. C-reactive protein and high-sensitivity C-reactive protein: an update for clinicians. Postgrad Med. 2011;123(1):114-119.

32. Man SF, Connett JE, Anthonisen NR, Wise RA, Tashkin DP, Sin DD. C-reactive protein and mortality in mild to moderate chronic obstructive pulmonary disease. Thorax. 2006;61(10):849-853.

33. Hogg JC, Chu F, Utokaparch S, et al. The nature of small-airway obstruction in chronic obstructive pulmonary disease. $N$ Engl J Med. 2004; 350(26):2645-2653.

34. Sturton G, Persson C, Barnes PJ. Small airways: an important but neglected target in the treatment of obstructive airway diseases. Trends Pharmacol Sci. 2008;29(7):340-345.

35. Ferrer M, Villasante $\mathrm{C}$, Alonso J, et al. Interpretation of quality of life scores from the St George's Respiratory Questionnaire. Eur Respir J. 2002;19(3):405-413.

36. Stojkovic J, Stevcevska G. Quality of life, forced expiratory volume in one second and body mass index in patients with COPD, during therapy for controlling the disease. Prilozi. 2009;30(1):129-142.

37. Maziak W, Loukides S, Culpitt S, Sullivan P, Kharitonov SA, Barnes PJ. Exhaled nitric oxide in chronic obstructive pulmonary disease. Am J Respir Crit Care Med. 1998;157(3 Pt 1):998-1002.

38. Nural S, Günay E, Halici B, Celik S, Ünlü M. Inflammatory processes and effects of continuous positive airway pressure (CPAP) in overlap syndrome. Inflammation. 2013;36(1):66-74.

39. Zakrzewicz D, Eickelberg O. From arginine methylation to ADMA: a novel mechanism with therapeutic potential in chronic lung diseases BMC Pulm Med. 2009;9:5.

40. Chung KF. Cytokines in chronic obstructive pulmonary disease. Eur Respir J Suppl. 2001;34:50s-59s. 
41. Ricciardolo FL, Nijkamp FP, Folkerts G. Nitric oxide synthase (NOS) as therapeutic target for asthma and chronic obstructive pulmonary disease. Curr Drug Targets. 2006;7(6):721-735.

42. Hart LA, Krishnan VL, Adcock IM, Barnes PJ, Chung KF. Activation and localization of transcription factor, nuclear factor-kappaB, in asthma. Am J Respir Crit Care Med. 1998;158(5 Pt 1):1585-1592.

43. Sankaralingam S, Xu H, Davidge ST. Arginase contributes to endothelial cell oxidative stress in response to plasma from women with preeclampsia. Cardiovasc Res. 2010;85(1):194-203.
44. Chandra S, Romero MJ, Shatanawi A, Alkilany AM, Caldwell RB, Caldwell RW. Oxidative species increase arginase activity in endothelial cells through the RhoA/Rho kinase pathway. Br J Pharmacol. 2012;165(2):506-519.

\section{Publish your work in this journal}

The International Journal of COPD is an international, peer-reviewed journal of therapeutics and pharmacology focusing on concise rapid reporting of clinical studies and reviews in COPD. Special focus is given to the pathophysiological processes underlying the disease, intervention programs, patient focused education, and self management protocols.

\section{Dovepress}

This journal is indexed on PubMed Central, MedLine and CAS. The manuscript management system is completely online and includes a very quick and fair peer-review system, which is all easy to use. Visit $\mathrm{http}: / / \mathrm{www}$. dovepress.com/testimonials.php to read real quotes from published authors.

Submit your manuscript here: http://www.dovepress.com/international-journal-of-chronic-obstructive-pulmonary-disease-journal 